\title{
COSTUS SPECIOSUS AND ITS ANTIPSORIATIC ARTHRITIS ACTIVITY: A REVIEW
}

\section{DEBPRATIM CHAKRABORTY*, NISHA LAMA YOLMO}

Department of Pharmaceutical Technology, Jadavpur University, Kolkata - 700 032, West Bengal, India. Email: debpratim008@gmail.com Received: 05 June 2018, Revised and Accepted: 28 August 2018

\section{ABSTRACT}

Objective: Psoriatic arthritis is an autoimmune disease. The marketed drugs cannot totally cure the disease state as well as they have severe side effects and for that reason researcher and scientists are going for traditional medicines. Costus speciosus is the plant of choice for its several positive activities against psoriatic arthritis.

Methods: Wistar albino healthy rat was taken for $0.1 \mathrm{ml}$ of Freund adjuvant-induced anti-arthritic and anti-inflammatory test, and diclofenac sodium $(15 \mathrm{mg} / \mathrm{kg})$ was taken as standard drug. The paw volume was measured at different time $1^{\text {st }}, 7^{\text {th }}, 14^{\text {th }}$, and $21^{\text {st }}$ days of experiment. In another study, the protocol is same, but indomethacin $(10 \mathrm{mg} / \mathrm{kg})$ was taken as standard drug. Another study was performed to know that the plant drug has any lipopolysaccharide (LPS)-stimulated COX-protein inhibitor activity or not. An acute anti-inflammatory property was studied in carrageenan-induced paw edema and result is measured by plethysmometer. The chronic anti-inflammatory property was studied by cotton pellet-induced granuloma formation. $400 \mathrm{mg} / \mathrm{kg}$ and $800 \mathrm{mg} / \mathrm{kg}$ dose of ethanolic extract is administered to the animal of both acute and chronic studies.

Results: In anti-arthritic and anti-inflammatory study, after the $21^{\text {st }}$ day, it has found that standard drug (diclofenac sodium) decreases paw volume $40 \%$ where the plant drug reduces it $68.33 \%$ \& $75.50 \%$ at higher and lower dose respectively. In the other study the Standard drug (Indomethacin) show arthritic score of 0.83 and the extract shows 1.67 at its higher concentration. In LPS-stimulated cyclooxygenase-2 (COX-2) inhibition study, extract helps to decrease the LPS-stimulated COX-2 protein nearly similar as methotrexate without any side effect. In the cotton pallet-induced antiinflammatory study, $400 \mathrm{mg} / \mathrm{kg}$ and $800 \mathrm{mg} / \mathrm{kg}$ dose of ethanolic extract shows similar result against standard drug.

Conclusion: Although its activity is less compared to the marketed drug, in the other sides, it has very mild adverse effect compared to the marketed Drug. It can be used as a supportive drug in the treatment of Psoriatic arthritis and by chemical modification the activity may be increased without any side effect.

Keywords: Costus speciosus, Psoriatic arthritis, Anti-inflammatory.

(C) 2019 The Authors. Published by Innovare Academic Sciences Pvt Ltd. This is an open access article under the CC BY license (http://creativecommons. org/licenses/by/4. 0/) DOI: http://dx.doi.org/10.22159/ajpcr.2019.v12i1.20430

\section{INTRODUCTION}

Psoriatic arthritis is an autoimmune disease that is why there is no such medicine which can fully cure that disease. The marketed drugs partially give some extent of relief but along with this that drugs produce a lot of side effects which ultimately make the patients physical condition worse. That is why scientists are trying to bring a new drug with same efficiency with minimum side effects.

Psoriasis is a long-lasting (chronic) inflammatory dermatitis which is characterized by brownish-red papules and plaques which are very sophisticated and covered with very fine silver-colored scales. Psoriatic arthritis is an associated disease of psoriasis. Psoriatic arthritis is similar as other arthritic conditions characterized by pain, stiffness mainly at the joint [1].

The signs and symptoms of psoriatic arthritis are very much similar with osteoarthritis and rheumatoid arthritis, and the main difference in case of osteoarthritis and rheumatoid arthritis is the appearance of the psoriasis/psoriatic patches (brownish-red patch) along with signs and symptoms of arthritis [2].

In most of the cases, first psoriasis or psoriatic patch is observed, then we realize the arthritic pain and stiffness, but in few cases, it also happened that first we get the osteoarthritis and rheumatoid arthritis signs and symptoms and after a few days the psoriatic patch appears.

Psoriatic arthritis is more frequent between the age of 30 and 55 [3]. It is more common in child than Adult [4]. Men and women are nearly equally affected (0.7:1) [4]. One of every 100 people is affected [1]. Indians have found highest prevalence (Fig. 1) [4]. At about $15 \%$ of case of psoriasis developed into psoriatic arthritis [5] and more than $80 \%$ of patients of psoriatic arthritis have psoriatic nail lesion.

Psoriatic arthritis is classified as a seronegative spondyloarthropathy and, therefore, occurs commonly in patients with tissue type human leukocyte antigen B27 [5].

\section{WHY WE WILL CHOOSE TRADITIONAL MEDICINE}

In modern medicine, there is no satisfactory effective therapy is still available to cure the psoriatic arthritis. Our ultimate option is the marketed medicines, but they have several drawbacks. The nonsteroidal anti-inflammatory drugs and cyclooxygenase (COX) inhibitor produce hepatic and renal toxicity.

Methotrexate - Stomach and intestine ulcer, bleeding, hole in intestine, decrease platelet, sepsis, and hypersensitivity bacterial infection [6].

Cyclosporine - Dizziness, flushing, increase blood pressure, nausea, vomiting, stomach upset, and diarrhea.

Sulfasalazine - Hyperreactivity, headache, nausea, vomiting and stomach upset, and hemolytic anemia [7].

Recombinant DNA technology is not that much effective still now and last option surgery is very much expensive that is why middle class and poor people cannot choose it. Until now, we are unable to find a safe drug 
or chemical moiety with minimal adverse effects, which can be taken for long durations and which will have optimum potency. For these above-mentioned reasons recently, there has been increasing interest in the use of medicinal plants. The use of medicinal plants in modern medicine suffers from the fact that though hundreds of plants are used in the world to prevent or cure diseases. However, today, it is necessary to provide scientific justification for the use of plant or its active principles.

\section{Plant details}

- Kingdom: Plantae

- Order: Zingiberales

- Family: Costaceae

- Genus: Cheilocostus

- Species: Speciosus

\section{Plant macroscopic study}

Costus speciosus is Commonly available in greater Sudanisl and Indonesia [8].

Plant height: $2.7 \mathrm{~m}$ high.

Root: Tuberous

Stem: Subwoody at the base and gradually juicy.

Leaves: Oblong, spirally arranged, subsessile, silky-pubescent beneath, and sheaths coriaceous.

Flower: Dense spike, bracts orate, mucronate, bright red, corolla tube short (yellow center and lip white color flower).

Fruits: Capsule, globosely trigonus, red.

Seed: Black with white aril.

\section{MICROSCOPY}

The rhizome of Costus speciosus contains visible periderm, periderm with stratified cork cells is also observed. The vascular bundle contains xylem, phloem, bundle sheath surrounded by fibers, and parenchymatous ground tissue. The vascular bundles are crescent shaped consisting of sclerenchymatous fibers surrounding bundle sheath, xylem, and phloem [9].

\section{Phytochemical parameters}

\begin{tabular}{lc}
\hline Parameters & Content (\%) \\
\hline Ash value & \\
Total ash & 4.25 \\
Acid-insoluble ash & 1.0 \\
Water-soluble ash & 2.5 \\
Moisture content & 3.3 \\
Phytoconstituents [Table 1] & \\
\hline Alkaloid & Absent \\
\hline Glycoside & Present \\
Flavonoid & Absent \\
Saponin & Present \\
Terpenoid & Absent \\
Steroid & Absent \\
Volatile oil & Absent \\
\hline
\end{tabular}

Animal model study of $C$. speciosus

Animal - Wistar albino rat (150-200 g) [10]

Condition-temperature $-25^{\circ} \mathrm{C} \pm 0.5^{\circ} \mathrm{C}$

Relative humidity - 55-65.

Food and water ad libitum.

In this study [Table 2], the anti-inflammatory activity of the plant drug is tested where the animals (rat) paw volume is measured at different time $1^{\text {st }}, 7^{\text {th }}, 14^{\text {th }}$, and $21^{\text {st }}$ days of experiment. After the $21^{\text {st }}$ day, it has found in this study that Standard drug decrease paw volume $40 \%$ where the plant drug reduces it $68.33 \% \& 75.50 \%$ at higher $(800 \mathrm{mg} / \mathrm{kg})$ and lower dose $(400 \mathrm{mg} / \mathrm{kg})$, respectively [11].

The biochemical parameters such as serum glutamic oxaloacetic transaminase (SGOT), serum glutamic pyruvic transaminase (SGPT), and alkaline phosphatase (ALP) also checked [Table 3] for getting drugs anti-inflammatory activity [11]

In another study [12],

Animal Wistar albino rat (150-200 g) of either sex.

Optimum condition-temperature $-25^{\circ} \mathrm{C} \pm 0.5^{\circ} \mathrm{C}$

Relative humidity - 55-65.

Food and water ad libitum.

Tumor necrosis factor- $\alpha$ (TNF- $\alpha$ ) increase that means the disease is an immunogenic disease. Here, in the study, they showed that plant has ability to decrease the TNF- $\alpha$ level. Hence, we may say that the plant has immunosuppressive effect [12]

SGOT, SGPT, and ALP level also decreases [12].

In another study [Table 4] [13], the methanolic extract of $C$. speciosus is tested in animals where the arthritis is induced on them by Freund's adjuvant. At a dose level of $400 \mathrm{mg} / \mathrm{kg}$ and $800 \mathrm{mg} / \mathrm{kg}$, it shows activity against paw edema (anti-inflammatory activity) 75.8 and 68.33\%, respectively. The SGOT, SGPT, and ALP level also estimated and it indicated very good anti-arthritis activity [14].

In another study [15], they tried to establish that the plant extract helps to decrease the LPS-stimulated TNF- $\alpha$ level nearly similar to methotrexate (Fig. 2).

COX-2 inhibition establishes that the plant extract has some antiinflammatory activity.

Sample with $50 \mathrm{mg} / \mathrm{ml}$ concentration helps to decrease the LPSstimulated COX-2 protein nearly similar as methotrexate without any side effect (Fig. 3) [15]

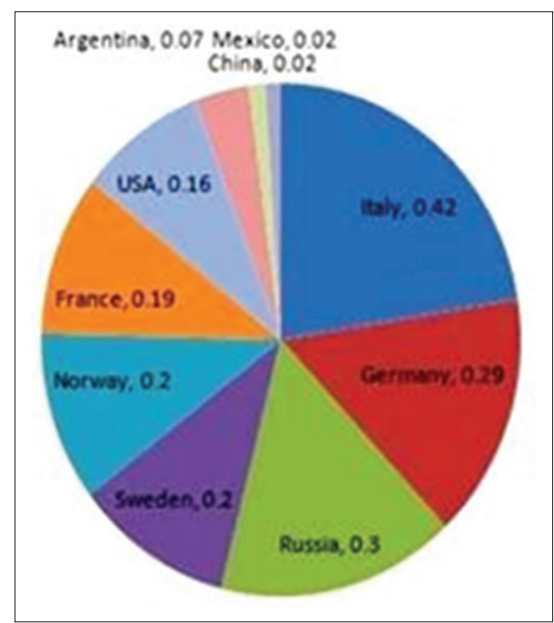

Fig. 1: Epidemiology of psoriatic arthritis

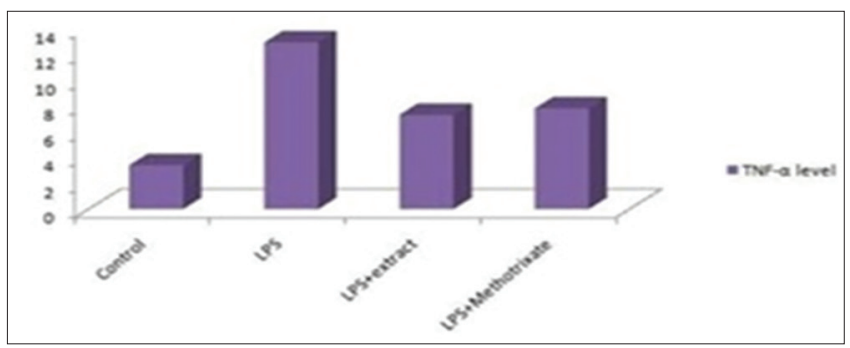

Fig. 2: Change of tumor necrosis factor- $\alpha$ level 
Table 1: Fluorescence study [9]

\begin{tabular}{llll}
\hline Type of extract & Visible light & UV at 254 $\mathbf{~ n m}$ (short UV) & UV at 365 nm (long UV) \\
\hline Aqueous extract & Brown & Light green & Cream \\
Chloroform extract & Brown & Dark green & Light brown \\
Ethanol extract & Dark brown & Green & Light brown \\
Methanol extract & Brown & Green & Dark brown \\
\hline
\end{tabular}

Table 2: Study protocol [11]

\begin{tabular}{|c|c|c|c|c|}
\hline Group No. & Group name & Arthritis-inducing agent & Drug & Others \\
\hline 1 & Control & $\mathrm{X}$ & $\mathrm{X}$ & CMC $1 \%(1 \mathrm{ml} / \mathrm{kg}$ b.w $)$ \\
\hline 2 & Standard & $0.1 \mathrm{ml}$ of Freund complete adjuvant & Diclofenac sodium (15 mg/kg) & CMC $1 \%(1 \mathrm{ml} / \mathrm{kg}$ b.w $)$ \\
\hline 3 & Test $_{400}$ & $0.1 \mathrm{ml}$ of Freund complete adjuvant & Test drug $(400 \mathrm{mg} / \mathrm{kg})$ & CMC $1 \%(1 \mathrm{ml} / \mathrm{kg}$ b.w $)$ \\
\hline 4 & Test $_{800}$ & $0.1 \mathrm{ml}$ of Freund complete adjuvant & Test drug $(800 \mathrm{mg} / \mathrm{kg})$ & CMC $1 \%(1 \mathrm{ml} / \mathrm{kg} \mathrm{b.w})$ \\
\hline
\end{tabular}

CMC: Carboxymethyl cellulose

Table 3: SGOT and SGPT level [11]

\begin{tabular}{lll}
\hline Drug & SGOT level & SGPT level \\
\hline Diclofenac & 63 & 73.5 \\
Test drug (400) & 85 & 92.5 \\
Test drug (800) & 78.8 & 89.5 \\
\hline
\end{tabular}

SGOT: Serum glutamic oxaloacetic transaminase, SGPT: Serum glutamic pyruvic transaminase

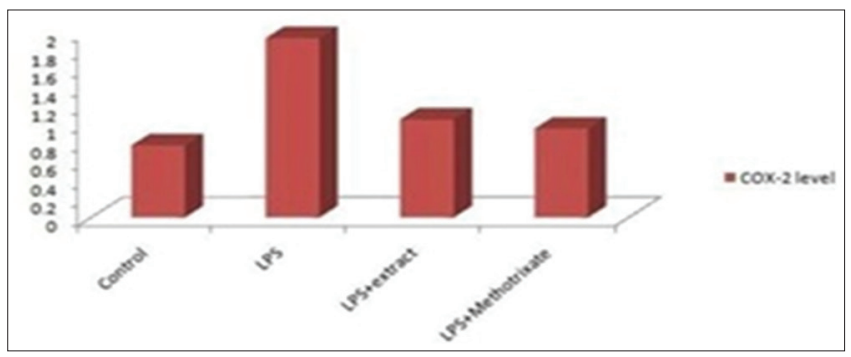

Fig. 3: Change of cyclooxygenase-2 level

In another study [16], it has been concluded that ethanolic extract of C. speciosus rhizome has anti-inflammatory [Tables 6 and 7]and anti-arthritic activity [Table 5]. An acute anti-inflammatory property was studied in carrageenan-induced paw edema and result is measured by plethysmometer. A chronic anti-inflammatory property was studied by cotton pellet-induced granuloma formation. $400 \mathrm{mg} / \mathrm{kg}$ and $800 \mathrm{mg} / \mathrm{kg}$ dose of ethanolic extract [16] is administered to the animal of both acute and chronic studies and the both studies show positive result [16].

\section{Other activities of $C$. speciosus}

\section{Antidiabetic effect}

Hexane, ethanolic, acetate, methanolic, and aqueous extract of C. speciosus are administered to streptozotocin $(50 \mathrm{mg} / \mathrm{kg})$-induced diabetic rat at a dose of 250 and $400 \mathrm{mg} / \mathrm{kg}$, respectively. The aqueous and methanolic extracts are most effective for lowering the plasma glucose concentration. It also normalized the other biological parameters associated with diabetes $[17,18]$.

\section{Antioxidant activity}

The plant has a strong antioxidant activity. Superoxide and peroxide test has been performed and it has been concluded that all the parts have more or less antioxidant activity. A study showed that chloroform extract of $C$. speciosus has free radical scavenging activity [19].

\section{Antibiotic activity}

Different extract of plant has antibacterial activity against microorganism such as Streptococcus, Escherichia coli, Pneumonia,
Pseudomonas, Bacillus, and Salmonella (activity measured by disc diffusion method) [20].

\section{Antifungal activity}

Various chemical constituents have been isolated and the activity is analysed on Alternaria sp., A. tenuissima, Botrytis cinerea and Fusarium lini etc. It has been observed that the isolated component has more or less activity [21,22].

\section{Antifertility activity}

The saponins present in C. speciosus rhizome are most effective produce antifertility activity on rat at a dose range of $5-500 \mu \mathrm{g} / 100 \mathrm{~g}$ b.w [23].

\section{Spasmolytic activity}

It has been proved that the plant extract expresses a wide angle nonspecific spasmolytic activity tested on guinea pig ileum [24].

\section{Hepatoprotective activity}

The hepatoprotective activity of ethanolic extract of $C$. speciosus rhizome was evaluated on $\mathrm{CCl}_{4}$-induced rat [25].

The SGOT, SGPT, ALP, and serum bilirubin are significantly decreased compared to the control; the histopathology also indicates a positive response of the plant extract.

\section{Anticholinesterase activity}

The alkaloids present in the plant extract possess anticholinesterase activity in both in vitro and in vivo (activity observed on frog rectus muscle and dog blood pressure).

\section{Estrogenic activity}

$1600 \mu \mathrm{g}$ of diosgenin isolated from C. speciosus approximately produce similar activity of $150 \mu \mathrm{g}$ of neoclinestrol [23].

\section{Anticariogenic activity}

The extract has anticariogenic activity.

\section{CONCLUSION}

From the above study, it can be concluded that C. speciosus is an effective drug that can be used in psoriatic arthritis. Although its activity is less compared to the marketed drug, in the other sides, it has very mild adverse effect compared to the marketed drug; it can be used as a supportive drug in the treatment of psoriatic arthritis. If the chemical constituent can be identified which is mainly responsible for anti-arthritic activity, then by molecular modification, the therapeutic activity may be increased as much as the marketed drugs and that will open a new way for all of us. 
Table 4: Treatment protocol [12]

\begin{tabular}{|c|c|c|c|c|}
\hline Group No. & Group name & Arthritis-inducing agent & Drug & Others \\
\hline 1 & Control & $\mathrm{X}$ & $\mathrm{X}$ & CMC $0.5 \%(1 \mathrm{ml} / \mathrm{kg} \mathrm{b.w})$ \\
\hline 2 & Standard & $0.1 \mathrm{ml}$ of Freund complete adjuvant $(1 \mathrm{mg} / \mathrm{kg})$ & Indomethacin $(10 \mathrm{mg} / \mathrm{kg})$ & CMC $0.5 \%(1 \mathrm{ml} / \mathrm{kg} \mathrm{b.w})$ \\
\hline 3 & Test $_{100}$ & $0.1 \mathrm{ml}$ of Freund complete adjuvant $(1 \mathrm{mg} / \mathrm{kg})$ & Test drug $(100 \mathrm{mg} / \mathrm{kg})$ & CMC $0.5 \%(1 \mathrm{ml} / \mathrm{kg} \mathrm{b.w})$ \\
\hline 4 & Test $_{200}$ & $0.1 \mathrm{ml}$ of Freund complete adjuvant $(1 \mathrm{mg} / \mathrm{kg})$ & Test drug (200 mg/kg) & CMC $0.5 \%(1 \mathrm{ml} / \mathrm{kg}$ b.w $)$ \\
\hline
\end{tabular}

*This protocol is continued for 28 days. 0-28 days the arthritic score and hind paw volume (marked) are measured. CMC: Carboxymethyl cellulose

Table 5: Arthritic score [12]

\begin{tabular}{llllll}
\hline Group & $\mathbf{0}^{\text {th }} \mathbf{d a y}$ & $\mathbf{7}^{\text {th }} \mathbf{d a y}$ & $\mathbf{1 4}^{\text {th }} \mathbf{d a y}$ & $\mathbf{2 1}^{\text {st }} \mathbf{d a y}$ & $\mathbf{2 8}^{\text {th }} \mathbf{d a y}$ \\
\hline Control & 1.67 & 3.67 & 3.67 & 3.83 & 3.50 \\
Standard & 1.83 & 2.16 & 1.67 & 1.34 & 0.83 \\
Test 100 & 1.84 & 3.83 & 3.67 & 3.00 & 2.17 \\
Test 200 & 2.00 & 3.66 & 3.83 & 2.67 & 1.67 \\
\hline
\end{tabular}

*All values are approximately changed $\pm 0.2-0.3$ (arthritic score - redness, swelling, and pain of joint)

Table 6: Determining inflammation by measuring paw volume [13]

\begin{tabular}{llllll}
\hline Group & $\mathbf{0}^{\text {th }} \mathbf{d a y}$ & $\mathbf{7}^{\text {th }} \mathbf{d a y}$ & $\mathbf{1 4}^{\text {th }}$ day & $\mathbf{2 1}^{\text {st }} \mathbf{d a y}$ & $\mathbf{2 8}^{\text {th }} \mathbf{d a y}$ \\
\hline Control & 2.92 & 3.29 & 3.25 & 3.15 & 3.16 \\
Standard & 2.93 & 1.88 & 1.57 & 1.39 & 1.3 \\
Test100 & 2.53 & 2.98 & 3 & 2.78 & 2.16 \\
Test200 & 2.58 & 2.93 & 2.86 & 2.48 & 1.9 \\
\hline
\end{tabular}

Table 7: Pain test [12]

\begin{tabular}{llllll}
\hline Group & $\mathbf{0}^{\text {th }}$ day & ${\mathbf{7}^{\text {th }}}^{\text {day }}$ & $\mathbf{1 4}^{\text {th }}$ day & $\mathbf{2 1}^{\text {st }}$ day & $\mathbf{2 8}^{\text {th }}$ day \\
\hline Control & 0.22 & 0.2 & 0.2 & 0.13 & 0.09 \\
Standard & 0.20 & 0.29 & 0.28 & 0.34 & 0.49 \\
Testl00 & 0.23 & 0.20 & 0.168 & 0.178 & 0.228 \\
Test200 & 0.251 & 0.215 & 0.17 & 0.185 & 0.23 \\
\hline
\end{tabular}

\section{AUTHORS' CONTRIBUTIONS}

Debpratim Chakraborty conceived of the presented idea. Nisha Lama Yolmo developed the matter and performed the computation. Debpratim Chakraborty has verified the data and methods. Prof. (Dr.) S. C. Mandal has investigated and verified this work. All the authors discussed the conclusion and contributions to the final manuscript.

\section{CONFLICTS OF INTEREST}

All authors have read the journal's policy on disclosure of potential conflicts of interest and have none to declare.

\section{REFERENCES}

1. Mohan H. Textbook of Pathology. $6^{\text {th }}$ ed. New Delhi: Jaypee Brothers; 2010.

2. Amherd-Hoekstra A, Näher H, Lorenz HM, Enk AH. Psoriatic arthritis: A review. J Dtsch Dermatol Ges 2010;8:332-9.

3. Epidemiology of Psoriatic Arthritis. WebMD LLC. Available from: https://en.wikipedia.org/wiki/Psoriatic_arthritis. [Last accessed on Retrieved 2011 May 04].

4. Available from: https://www.en.wikipedia.org/wiki/Psoriatic_arthritis.
5. Liu JT, Yeh HM, Liu SY, Chen KT. Psoriatic arthritis: Epidemiology, diagnosis, and treatment. World J Orthop 2014;5:537-43.

6. Gaies E, Jebabli N, Trabelsi S, Salouage I, Charfi R, Lakhal M, et al. Methotrexate side effects: Review article. J Drug Metab Toxicol 2012;3:125.

7. Available from: https://www.en.wikipedia.org/wiki/Sulfasalazine\#Side effects.

8. Available from: https://www.hort.purdue.edu/newcrop/CropFactSheets/ costus.html.

9. Kala C, Ali SS, Chaudhary S. Comparative pharmacognostical evaluation of Costus speciosus (Wild ginger) and Zingiber officinale (Ginger) rhizome. Int J Curr Pharm Res 2016;8:1-5.

10. Sarimanah J, Adnyana IK, Sukandar EI, KurnIati NE. The antirheumatic activity of Muntingia calabura L. Leaves ethanol extract and its fraction. Asian J Pharm Clin Res 2017;10:84-6.

11. Srivastava S, Singh P, Jha KK, Mishra G, Srivastava S, Khosa RL. Evaluation of antiarthritic potential of the methanolic extract of the aerial parts of Costus speciosus. J Ayurveda Integr Med 2012;3:204-8.

12. Kala C, Ali SS, Abid M, Sharma US, Khan NA. Evaluation of in vivo antiarthritic potential of methanolic extract of Costus speciosus rhizome. J Appl Pharm Sci 2015;5:46-53.

13. Annavarapu TR, Renuka P, Akhil P, Divya P, Devi PP. Evaluation of the anti-inflammatory activity of combination of ethanolic extract of Azadirachta indica (Neem) and Lawsonia inermis (Henna). Asian J Pharm Clin Res 2016;9:256-8.

14. Sushilkumar PN, Neelavathy R. Herbs used in the treatment of arthritis-A review. WJPMR 2016;2:47-56.

15. Selima S, Jaounia SA. Anti-Inflammatory, antioxidant and antiangiogenic activities of diosgenin isolated from traditional medicinal plant. Costus speciosus (Koenex.Retz.) Sm. Nat Prod Res 2016;30:1830-3

16. Reddy VS, Rao GN, Lakshmi RG. A review on anti-arthritic activity on some medicinal plant. J Glob Trends Pharm Sci 2014;5:2061-73.

17. Vishalakshi D, Urooj A. Hypoglycemic potential of Morus indica L. Costusigneus. Nak- A preliminary study. Indian J Exp Biol 2008;46:614-6.

18. Eliza J, Daisy P, Ignacimuthu S. Influence of Costus speciosus (Koen.) Sm. Rhizome extracts on biochemical parameters in streptozotocin induced diabetic rats. J Health Sci 2008;54:675-81.

19. Vijayalakshmi A, Sarada NC. Screening of Costus speciosus extracts for antioxidant activity. Fitoterapia 2008:79:197-8

20. Malabadi RB, Antibacterial activity in the rhizome extract of Costus speciosus (Koen.). J Phytol Res 2005;18:83-5.

21. Singh UP, Srivsastava BP, Singh KP, Pandey VB. Antifungal activity of steroid saponins and sapogenins from Avena sativa and Costus speciosus. Nat Sao Paulo 1992;17:71-7.

22. Bandara BM, Fernando IH, Hewage CM, Karunaratne V, Adikaram NK, Wijesundara DS. Antifungal activity of some medicinal plants of Sri Lanka. J Nat Sci Counc Sri Lanka 1989;17:1-13.

23. Tewari PV, Chaturvedi C, Pandey VB. Antifertility activity of Costus speciosus Sm. Ind J Pharm 1973;35:114-5.

24. Banerji R, Prakash D, Patnaik GK, Nigam SK. Spasmolytic activity of saponins. Ind Drugs 1982;20:51-4.

25. Mishra G, Sinha R, Verma N, Khosa RL, Garg VK, Singh P. Hepatoprotective activity of aqueous and alcoholic extract of Wedelia chinensis. Pharm Online 2009;1:343-56. 